\title{
Risk Assessment on Debris Flow Hazard along Linear Construction Civil Engineering Based on Satellite Remote Sensing and Fuzzy Comprehensive Evaluation Method
}

\author{
Xiao-Ying Lee \\ majoring in mineral prospecting and exploration \\ HengShui City.Hebei Province, China \\ e-mail: 627305807@qq.com
}

\author{
Ke-Cheng Lee \\ Beijing University of Aeronautics and Astronautics \\ majoring in Civil Engineering \\ ShiJiazhuang City.Hebei Province, China \\ e-mail: 189992431@foxmail.com
}

\begin{abstract}
Taking the Lixian-Guangyuan segment of Lanzhou-Chengdu-Chongqing product oil pipeline as an example, the satellite images in the study area were produced based on multi-source remote sensing information. The authors then established the remote sensing interpretation signs for debris flows according to the data of geological and ecological environment. After that, the 3D remote sensing image models of debris flows were constructed by texture mapping technique and DEM (Digital Elevation Model). Based on the satellite images and the 3D models, debris flows along the pipelines were identified, and their features were extracted for risk assessment, which were designed into the different evaluation indexes. The authors thus introduced fuzzy comprehensive evaluation model to assess the debris flows based on these evaluation indexes. According to field investigation, the identified and evaluated results were checked to be well. It is obvious that this assessment method can quickly identify debris flows along linear construction civil engineering and evaluate their risk, which would provides scientific basis for engineering disaster prevention.
\end{abstract}

Keywords-Oil pipeline;Remote sensing detection;3D model;Debris flow hazard;Fuzzy comprehensive evaluation model

\section{FOREWORD}

Line engineering refers to the engineering with large length-width ratio, which typically extends up to dozens of kilometers and even thousands of kilometers. Inevitably, it is affected by some geological disasters, such as landslide, mudslide ${ }^{[1]}$. So, it is particularly important to make correct evaluation on the development trend and risks of geological hazards through effectively capturing and identifying the relevant information along the pipeline during the period of line engineering survey and design. Taking the Lixian-Guangyuan segment of Lanzhou-Chengdu-Chongqing product oil pipeline as an example ${ }^{[2]}$, this paper explores how to use the remote sensing technology to identify the debris flows along the pipeline and extract information on the characteristics of debris flow hazard. In addition, through using the information, an evaluation model of debris flow risks is established on the basis of analytic hierarchy process and fuzzy comprehensive evaluation model, forming a rapid and effective method for remote sensing identification of debris flow along the engineering and the relevant hazards assessment.

\section{RECOGNITION OF DEBRis Flow AND EXTRACTION OF INFORMATION ON ITS CHARACTERISTICS}

Recognition of debris flow disaster is based on the the comprehensive collection and analysis of data related to the existing remote sensing image, regional geology, hydrology engineering geology, meteorology and hydrology and human environment. Specifically, the remote sensing recognition mark of debris flow is first established along the pipeline zones, and then the distribution status of debris flow in the work areas is preliminarily interpreted. On this basis, the field verification is conducted to amend the preliminary interpretation.

\section{A. Scope of interpretation}

It covers the scope of alongside the oil and gas pipelines and both sides of them. It concerns the section of from Red River to the east of Lixian in Gansu Province to Guangyuan City in Sichuang Province southward; in view of the consideration of water system basin, either side extends outward for $15 \mathrm{~km}$.

\section{B. Interpretation base map and minimum interpretable} debris flow size

Remote sensing data come from the ETM + (Enhanced Thematic Mapper Plus) image data (15meter panchromatic +30 -meter multi-spectral) View 2 captured by LandSAT-7 satellite in December 2013, and the interpretation is based on the reference to IRS-P5 satellite images (2.5-meter-panchromatic). As the remote sensing image resolution in this study is $15 \mathrm{~m}$, according to the study of Zhong Yanjiang ${ }^{[3]}$, in the case of using the remote sensing image interpretation, the theoretical minimum value of interpretable debris flow size is $3 \times$ $3=9$ pixels, but the actual value is greater than $7 \times$ $11=77$ pixels. Therefore, for the interpretable base map in this study, the theoretical minimum interpretable debris flow size is $45 \mathrm{~m} \times 45 \mathrm{~m}$, about $0.002 \mathrm{~km}^{2}$; actually, the 
minimum interpretable debris flow size is $105 \mathrm{~m} \times 165 \mathrm{~m}$, about $0.017 \mathrm{~km}^{2}$.

\section{Interpretation results}

Using the interpretation base map and threedimensional model of remote sensing image ${ }^{[4]}$, the systematic interpretation of Lixian-Guangyuan segment of Lanzhou-Chengdu-Chongqing product oil pipeline based on the established interpretation marks. Let's take the debris flow in the Liyugou Valley as an example (Fig1.). Seen from remote sensing image, the bottom and mouth of this valley have lighter tone and the the valley side in the upper reach have the lighter tone mostly, which forms the patterns of spots or patches; the valley bottom in the upper reach is relative wide, and the valley foot at the lower part of the southern valley side is usually the scarp and the ascending slope is relatively steep; the gullies on the valley side are not well-developed, which are sheet flow erosion-based; the valley in the downstream is narrow V-shaped valley; at the mouth of valley, there are small-sized alluvial fans, which protrude towards the valley direction.

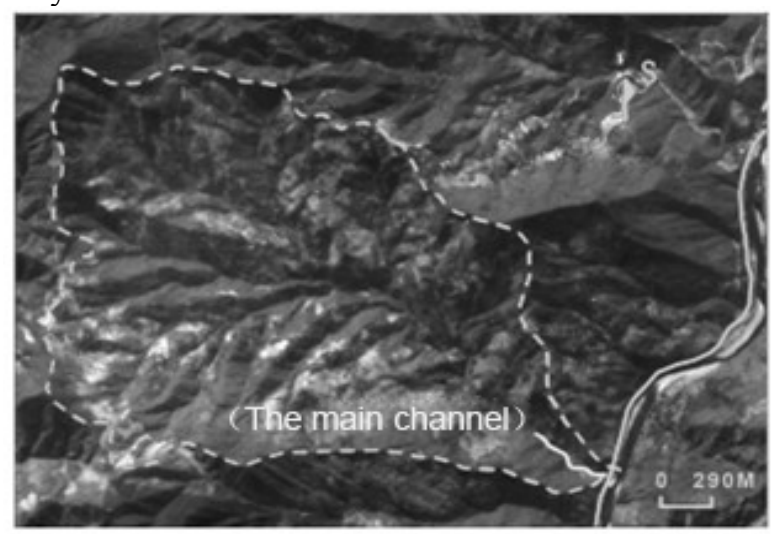

Figure 1. Three-dimensional Remote Sensing Image Model of Debris Flow of Liyugou Valley

There are a total of eight debris flow valleys which are interpreted (Numbered N1-N8) . For the interpreted debris flow valley, the field verification is conducted. The situation in the field shows that, of eight debris flow valleys interpreted, some valleys have the developing deposits at the mouth, and the transport materials are the extremely uneven stones; these debris flow valleys have better interpretation results. But for those valleys with non-developed deposits at the mouth ${ }^{[6]}$, they are easily forgotten in the interpretation.

\section{EXTRACTION OF INFORMATION ON CHARACTERISTICS OF DEBRIS Flow ALONG THE PIPELINE}

The information extraction follows one principle: By means of a 3D model of remote sensing image, the focus is extended to the geological environment of disaster source area from the point where the disaster occurs to extract the characteristic parameter of disaster points.

The method of extraction: Based on the twodimensional image and 3D model, the information on the length, area and index is extracted on the two-dimensional planar image; the information on the elevation and slope is extracted on the three-dimensional space.

The extractable parameters include: morphological characteristics of debris flow, area of the river basin (S1), length of main valley (S2, mainly the length of valley in the flow area), the maximum difference in relative elevation of the river basins (S3), the cutting density of river basin (S6, the total length of valley in the unit area), the bending modulus of main valley (S7) and so on. In addition, although the maximum (possible) debris flowout amount and the frequency of debris flow ${ }^{[5]}$ occurrence cannot be directly obtained, using the above parameter values, they can be figured out indirectly through the following formula:

$$
\begin{gathered}
\mathrm{L}_{1}=0.97 \times\left(-2+0.26 \mathrm{~S}_{1}+0.41 \mathrm{~S}_{6}+0.021 \mathrm{~S}_{8}\right) \\
\mathrm{L}_{2}=0.882 \times\left(-80.6596-2.8302 \mathrm{~S}_{1}+12.138 \mathrm{~S}_{6}+0.0209 \mathrm{~S}_{8}\right)
\end{gathered}
$$

In the formula, L1 is the maximum flowout amount of debris flow; L2 is the frequency of debris flow occurence; $\mathrm{S} 1$ is the area of river basin; S6 is the cutting density of river basin; $\mathrm{S} 8$ is the total reserves of loose solid materials in the river basin, which is figured out according to Formula (3):

$$
\mathrm{S}_{8}=\left(\mathrm{L}-0.08061-0.0015 \mathrm{~S}_{1}\right) / .000033
$$

In the formula, $\mathrm{L}$ is the maximum deposit length of debris flow, which is figured out according to the following formula:

$$
\mathrm{L}=0.7523+0.0079 \mathrm{~S}_{1}+0.1655 \mathrm{~S}_{3}+0.0914 \mathrm{~S}_{2}-0.0207 \mathrm{G}
$$

In the formula, $\mathrm{G}$ is the average slope of main valleys, which can be extracted from three-dimensional images; the rest are the same as the above

Based on the above method, the characteristic factor

\begin{tabular}{|c|c|c|c|c|c|}
\hline $\begin{array}{c}\text { Serial } \\
\text { No. } \\
\end{array}$ & $\begin{array}{l}\mathbf{L}_{2} \text { (times/ } \\
\text { Century ) }\end{array}$ & $\begin{array}{c}\mathrm{S}_{1} \\
\left(\mathrm{~km}^{2}\right)\end{array}$ & $\mathrm{S}_{2}(\mathbf{k m})$ & $\mathrm{S}_{6}\left(\mathbf{k m} / \mathbf{k m}^{2}\right)$ & $S_{7}$ \\
\hline N1 & 44 & 1.8 & 1.00 & 7.40 & 1.140 \\
\hline N2 & 11 & 2.7 & 0.75 & 6.30 & 1.050 \\
\hline N3 & 36 & 9.7 & 1.20 & 5.79 & 1.140 \\
\hline N4 & 92 & 11.6 & 1.70 & 8.26 & 1.210 \\
\hline N5 & 31 & 5.7 & 1.40 & 4.64 & 1.100 \\
\hline N6 & 32 & 4.4 & 1.00 & 5.27 & 1.06 \\
\hline N7 & 39 & 3.6 & 1.20 & 5.38 & 1.120 \\
\hline N8 & 1 & 5.6 & 0.50 & 5.02 & 1.135 \\
\hline
\end{tabular}
values (Tab.1) of debris flows along the section of LixianGuangyuan are obtained.

TABLE 1. $\mathrm{T}_{\mathrm{ABLE}}$ for $\mathrm{C}_{\text {HaRActeristics }}$ of $\mathrm{D}_{\text {EBRis }} \mathrm{F}_{\mathrm{LOW}}$ in the $\mathrm{L}_{\mathrm{IXIAN}}$ -

\section{RISK ASSESSMENT ON DEBRIS FLOW HAZARD}

Debris flow is the comprehensive product of internal and external dynamic interaction and mutual coupling between regional topography and geomorphology,stratigraphic lithology, meteorology and hydrology, rainfall and vegetation coverage ${ }^{[7]}$. Many influential factors tend to have varying degrees of fuzziness, so people often use the fuzzy comprehensive evaluation method to analyze the risks of debris flow.

A. Establishment of analytic hierarchy model of assessment system

On the basis of taking the risk of debris flow hazard as the overall objective layer, the disaster-causing factors 
and topography factors as the layer of elements and the influential factors as the layer of evaluation factors, a hierarchical model is established.

\section{B. Construction of the judgment matrix}

Through using the 1-9 scale method proposed BY Saaty (1980) to make the pairwise comparison in the relative importance of factors at each layer to the target of the upper layer, the judgment matrix is established; then the maximum eigenvalue of the judgment matrix ${ }^{[8]}$, the corresponding characteristic vectors and single sequence of hierarchies are calculated; finally the the consistency of judgment matrix is tested through the following formula:

$$
\mathrm{CR}=\frac{C I}{R I}
$$

In this formula, $\mathrm{CR}$ is the random consistency ratio for judging matrix; RI is the mean random consistency index of judging matrix, the value of which are shown in Table 4; CI is the consistency index of judging matrix, which can be calculated through the following formula:

$$
\mathrm{CI}=\frac{1}{m-1}\left(\lambda_{\max }-m\right)
$$

In this formula, $\lambda_{\max }$ is the maximum eigenvalue; $m$ is the order of judgment matrix.

When CR is less than $0.1(\mathrm{CR}<0.1)$, it is agreed that the judgment matrix has the satisfactory consistency, indicating the weight distribution is reasonable; otherwise, it is necessary to adjust the judgment matrix until the satisfactory consistency is achieved.

TABLE 2. $\mathrm{M}_{\text {EAN }} \mathrm{R}_{\text {ANDOM }} \mathrm{C}_{\text {ONSISTENCY }} \mathrm{I}_{\text {NDEX }} \mathrm{V}_{\text {ALUeS }}$ of $\mathrm{A}_{\text {NALytic }} \mathrm{H}_{\text {IERARChY }}$ $\mathrm{M}_{\mathrm{ETHOD}}$

\begin{tabular}{ccccccc}
\hline $\boldsymbol{m}$ & 1 & 2 & 3 & 4 & 5 & 6 \\
\hline $\boldsymbol{R I}$ & 0 & 0 & 0.58 & 0.90 & 1.12 & 1.24 \\
\hline
\end{tabular}

C. Calculation results of assessment index weights The calculation results of judgment matrix at each layer are shown in Table 3 and Table 4.

TABLE 3. $\mathrm{J}_{\text {UdGMENT }} \mathrm{M}_{\text {ATRIX }}$ of $\mathrm{T}_{\text {OPOGRAPHY }} \mathrm{F}_{\text {ACTORS }}$

\begin{tabular}{ccccccc}
\hline $\mathbf{U}_{2}$ & $\mathbf{U}_{2 \mathbf{1}}$ & $\mathbf{U}_{\mathbf{2 2}}$ & $\mathbf{U}_{\mathbf{2 3}}$ & $\mathbf{U}_{\mathbf{2 4}}$ & $\mathbf{U}_{25}$ & $\mathbf{W}$ \\
\hline $\mathbf{U}_{2 \mathbf{2 1}}$ & 1 & 2 & 4 & 6 & 7 & 0.446 \\
$\mathbf{U}_{22}$ & $1 / 2$ & 1 & 3 & 5 & 6 & 0.297 \\
$\mathbf{U}_{23}$ & $1 / 4$ & $1 / 3$ & 1 & 3 & 4 & 0.144 \\
$\mathbf{U}_{24}$ & $1 / 6$ & $1 / 5$ & $1 / 3$ & 1 & 2 & 0.068 \\
$\mathbf{U}_{25}$ & $1 / 7$ & $1 / 6$ & $1 / 4$ & $1 / 2$ & 1 & 0.045 \\
\hline
\end{tabular}

TABLE 4. $\mathrm{T}_{\mathrm{ABLE}}$ for $\mathrm{C}_{\text {OMPREHENSIVE }} \mathrm{S}_{\text {CORING }}$ of $\mathrm{E}_{\text {LMENTS }}$

\begin{tabular}{cccc}
\hline $\mathbf{V}$ & $\mathbf{U}_{\mathbf{1}}$ & $\mathbf{U}_{2}$ & $\mathbf{W}$ \\
\hline $\mathbf{U}_{\mathbf{1}}$ & 1 & 1 & 0.5 \\
$\mathbf{U}_{2}$ & 1 & 1 & 0.5 \\
\hline
\end{tabular}

From the above three tables, the fuzzy subsets of importance of each factor and the maximum eigenvalues are obtained, which are as follows:

$$
\begin{gathered}
\bar{A}_{1}^{(2)}=(0.5,0.5), \lambda_{\max }=2 ; \\
{\overline{A_{2}}}^{(2)}=(0.446,0.297,0.144,0.068,0.045), \lambda_{\max }=5.139
\end{gathered}
$$

$$
{\overline{A_{1}}}^{(2)}=(0.5,0.5), \lambda_{\text {max }}=2
$$

Through Formula (5) and (6), the test indicators can be obtained, which are as follows:

$$
\begin{gathered}
C R_{1}^{(2)}=0.031<0.1 ; \\
C R_{2}^{(2)}=0<0.1 ; \\
C R^{(2)}=0<0.1 .
\end{gathered}
$$

It can be seen that each judgment matrix can meet the consistency test, indicating that the weight distribution is reasonable.

\section{COMPREHENSIVE ASSESSMENT ON RISKS OF DEBRIS FLOW HAZARD}

\section{A. Establishment of fuzzy assessment matrix}

According to the established assessment set "V", the indicators are assessed; that is, the fuzzy mapping of from $\mathrm{U}$ to $\mathrm{F}(\mathrm{V})$ is established, and the fuzzy transform matrix (R) composed of membership degree of of each factor "Ui" in the correspondence to each assessment level "Vj" is determined.

$$
\begin{aligned}
& R_{1}^{(2)}=\left[\begin{array}{l}
r_{11}{ }^{(2)} \\
r_{12}{ }^{(2)}
\end{array}\right]=\left[\begin{array}{cccc}
0 & 0.956 & 0.044 & 0 \\
0 & 0.7 & 0.300 & 0
\end{array}\right] \\
& R_{2}{ }^{(2)}=\left[\begin{array}{l}
r_{21}{ }^{(2)} \\
r_{22}{ }^{(2)} \\
r_{23}{ }^{(2)} \\
r_{24}{ }^{(2)} \\
r_{25}{ }^{(2)}
\end{array}\right]=\left[\begin{array}{cccc}
0.211 & 0.789 & 0 & 0 \\
0.02 & 0.98 & 0 & 0 \\
0.5 & 0.5 & 0 & 0 \\
0.839 & 0.161 & 0 & 0 \\
0.1 & 0.9 & 0 & 0
\end{array}\right]
\end{aligned}
$$

\section{B. Operation of comprehensive assessment}

The comprehensive assessment of the first layer is as follows:

$B_{1}^{(2)}={\overline{A_{1}}}^{(2)} R_{1}^{(2)}=(0,0.828,0.172,0)$

$B_{2}^{(2)}={\overline{A_{2}}}^{(2)} R_{2}^{(2)}=(0.234,0.766,0,0)$

Thus, the second-level fuzzy relation matrix is obtained:

$B_{1}^{(1)}=\left[\begin{array}{cccc}0 & 0.828 & 0.172 & 0 \\ 0.234 & 0.766 & 0 & 0\end{array}\right]$

So far, the comprehensive evaluation of the second layer can be made, generating the comprehensive assessment set of $\mathrm{N} 1$ debris flow valleys:

$A=\bar{A}_{1}^{(1)} B_{1}^{(1)}=(0.117,0.797,0.086,0)$

Other single debris flow calculation processes are similar, so it is not necessary to describe them one by one. Finally the comprehensive assessment results of eight single debris flows are obtained. $\mathrm{A}(\mathrm{N} 2)=(0.362,0.638,0,0)$ $\mathrm{A}(\mathrm{N} 3)=(0.118,0.594,0.288,0)$ $\mathrm{A}(\mathrm{N} 4)=(0.056,0.347,0.491,0.106)$ $\mathrm{A}(\mathrm{N} 5)=(0.175,0.616,0.209,0)$ $\mathrm{A}(\mathrm{N} 6)=(0.165,0.696,0.139,0)$ 


$$
\begin{gathered}
\mathrm{A}(\mathrm{N} 7)=(0.138,0.718,0.144,0) \\
\mathrm{A}(\mathrm{N} 8)=(0.776,0.224,0,0)
\end{gathered}
$$

\section{Determination of the hazard rank}

The values in the fuzzy assessment set correspond to the membership of security level; these values are used to determine the safety assessment level mainly in two ways: maximum membership assessment criterion and weighted calculating method ${ }^{[9,10]}$. In this paper, the maximum membership assessment criterion is used for judgment. For example, for N1, the comprehensive evaluation result is $\mathrm{A}(\mathrm{N} 1)=(0.117,0.797,0.086,0)$; then the maximum membership value is taken, that is, 0.797 , which is corresponding to Level $\mathrm{II}^{[11,12]}$. So, it can be determined that the hazard rank of this debris flow gully is moderate. The risk assessment results of eight single debris flows in the section of Lixian - Guangyuan are shown in Tab.5.

\begin{tabular}{|c|c|c|c|c|c|}
\hline $\begin{array}{c}\text { Serial } \\
\text { No. }\end{array}$ & $\begin{array}{c}\text { Hazard } \\
\text { rank }\end{array}$ & $\begin{array}{c}\text { Risk } \\
\text { assessment }\end{array}$ & $\begin{array}{c}\text { Serial } \\
\text { No. }\end{array}$ & $\begin{array}{c}\text { Hazard } \\
\text { rank }\end{array}$ & $\begin{array}{c}\text { Risk } \\
\text { assessment }\end{array}$ \\
\hline N1 & II & $\begin{array}{l}\text { Moderate } \\
\text { risk }\end{array}$ & N5 & II & $\begin{array}{l}\text { Moderate } \\
\text { risk }\end{array}$ \\
\hline $\mathrm{N} 2$ & II & $\begin{array}{l}\text { Moderate } \\
\text { risk }\end{array}$ & N6 & II & $\begin{array}{l}\text { Moderate } \\
\text { risk }\end{array}$ \\
\hline N3 & II & $\begin{array}{l}\text { Moderate } \\
\text { risk }\end{array}$ & N7 & II & $\begin{array}{l}\text { Moderate } \\
\text { risk }\end{array}$ \\
\hline N4 & III & High risk & N8 & I & Low risk \\
\hline
\end{tabular}

TABLE 5. $\mathrm{H}_{\text {AZARD }} \mathrm{R}_{\text {ANKS }}$ of $\mathrm{S}_{\text {INGLE }} \mathrm{D}_{\text {EBRIS }} \mathrm{F}_{\text {LOWS }}$

\section{VI.CONCLUSIONS}

According to the characteristics of deposits at the mouth of valley, the development stage of debris flow gulley can be roughly determined[1]; based on the ground conditions of debris flow gulley, such as topography, tectonic activity, lithology, loose materials, human activities and vegetation coverage, the activity of debris flow can be judged[2]. Taking N1 for example, there are more deposits of alluvial materials at the bottom and mouth of valley [3,4], but as the relatively complete fanshaped deposit landform has not yet been formed at the mouth of valley, this debris flow gulley has been in the stage of development at present[5]. In terms of ground conditions, influenced by the fracture movement, this debris flow gulley is characterized by more intense terrain incision[6], steep valley side, larger slope of main gulley, narrow valley and secondary gulley development on both sides; however, as the vegetation in the valley is dense and lush and there are rare human activities[7,8], it is considered that the debris flow gulley is more active. Similarly, N2 is at the stage of transition from development to recession, but it is still relatively active; $\mathrm{N} 3, \mathrm{~N} 4, \mathrm{~N} 5, \mathrm{~N} 7, \mathrm{~N} 8$ are in the development period[9,10], they are relatively active; of them, N4 has the higher hazard rank as it has the factors with larger values, such as area of river basin, length of main valley and basin incision density; but N8 is the opposite; although N6 is in the development stage, its activity level is general. The above analysis results[11,12] are basically in consistency with fuzzy comprehensive evaluation results, indicating that it is feasible to use fuzzy comprehensive evaluation method to make the risk assessment on the debris flow hazard.

\section{REFERENCES}

[1] Zhao Pengda. Quantitative Geoscience: Methods and Its Applications [M]. Higher Education Press, 2004

[2] Yin Kunlong. Landslide Hazard Prediction and Evaluation [M]. China University of Geosciences Press, 2004

[3] Liu Xilin, Mo Duowen, etc. Risk Assessment of Debris Flow Hazard[M]. Sichuan Science and Technology Press, 2003

[4] Liu Xilin, Tang Chuan. Assessment on Debris Flow Hazard[M]. Science Press, 1995

[5] Zhang Yue, etc. Fuzzy Mathematics Method and Its Application [M]. Coal Industry Publishing House, 1992

[6] [The Soviet Union],Флейшман, C•M•, (Translated by Yao Deji). Mudslides [M]. Science Press, 1986

[7] Panizza, M.Geomorphology and seismic risk. Earth Science Reviews. 1991

[8] Ash Robert R. Information Theory. Journal of Women's Health. 1990

[9] C. Tang,J. Zhu,W. L. Li,J. T. Liang. Rainfall-triggered debris flows following the Wenchuan earthquake[J]. Bulletin of Engineering Geology and the Environment . 2009 (2)

[10] Davide Tiranti,Sabrina Bonetto,Giuseppe Mandrone. Quantitative basin characterisation to refine debris-flow triggering criteria and processes: an example from the Italian Western Alps[J]. Landslides . 2008 (1)

[11] Fuchs S.,Heiss K.,Hübl J.. Towards an empirical vulnerability function for use in debris flow risk assessment[J]. Natural Hazards and Earth System Science . 2007 (70)

[12] Tung-Chiung Chang. Risk degree of debris flow applying neural networks[J]. Natural Hazards . 2007 